\title{
Reformas Liberais e Descentralização no Brasil (1990-2002): a atuação do Banco Nacional de Desenvolvimento Econômico e Social (BNDES)
}

Vico Dênis Sousa de Melo*

Resumo: Entre os anos de 1990 a 2002, sob os mandatos de Fernando Collor de Mello e Fernando Henrique Cardoso - resguardando o interregno do governo Itamar Franco - o Brasil deu início e aprofundou os processos de reformas liberais. Apesar de aderir tardiamente às reformas, em relação aos demais países da região sul-americana, nesse período o país passou por um processo amplo de transformações sociais, econômicas e administrativas. Essa reestruturação estava fundamentada na nova adequação do Brasil às transformações nas relações internacionais pós-Muro de Berlim. Portanto, o objetivo desse trabalho é o de analisar a relação entre o processo de reformas liberais empreendidos no país - em especial, as privatizações e abertura comercial, mas sem se furtar da descentralização em setores governamentais - com a estratégia de se tornar um Estado responsável e integrante no novo contexto global.

Palavras-chave: Brasil. Reformas Liberais. Privatizações. Abertura Comercial. Descentralização. BNDES.

\footnotetext{
* Doutorando bolsista da CAPES em Pós-Colonialismos e Cidadania Global no Centro de Estudos Sociais (CES) da Universidade de Coimbra (UC), é Mestre em Ciência Política pela Universidade Federal de Pernambuco (UFPE) e Bacharel em Relações Internacionais pela Universidade Estadual da Paraíba (UEPB). E-mail: vico_denis@hotmail.com
} 


\section{Introdução}

As chamadas reformas liberais de primeira geração, adotadas já a partir dos anos setenta em alguns países da América Latina ${ }^{1}$, mas disseminadas ao longo dos anos oitenta e noventa pela região, 6 tinham como fundamento dois componentes principais: o processo de desestatização da economia, impulsionado através da venda de empresas públicas, somado à abertura comercial através da diminuição das tarifas alfandegárias ou a supressão de barreiras técnicas; o processo de descentralização estatal a partir dos órgãos administrativos como forma de possibilitar maior participação popular e diminuir a corrupção no seu interior.

Em 1989, um grupo de economistas e funcionários de instituições financeiras multilaterais lançou um "receituário" de política econômica fundamentado nos preceitos liberais. Essa reunião ficou conhecida como o "Consenso de Washington", com intenções a alcançar uma solução definitiva para os problemas da dívida externa e inflação galopante nos países da América Latina. As conclusões principais ao fim da "reunião", foram propostas de reformulação do Estado através das reformas políticas e de mercado, pautadas pela disciplina fiscal, privatizações (empresas estatais e serviços públicos) e liberalização comercial.

As teorias (neo)liberais têm como fundamento a ideia de que a intervenção estatal é inútil e contraproducente e, que o aumento da inflação surge a partir de expectativas adversas e falta de credibilidade das políticas públicas. Nesse sentido, com intuito de aumentar a credibilidade e a retomada da eficiência econômica, há necessidade de promover a eliminação das pressões residuais provenientes da presença do Estado, liberalização de capitais, comercial e independência do Banco Central.

O Brasil aderiu tardiamente ao processo de reformas orientadas ao mercado quando comparado aos seus vizinhos sul americanos. Desde os anos 1950 a meados dos 1980, a política de desenvolvimento do Brasil se pautou nos preceitos desenvolvimentistas de substituição de importações a partir de uma forte industrialização de base ${ }^{2}$. Essa política condizia, à época, com o interesse de buscar autonomia internacional através da mudança na estrutura produtiva, 
até então predominantemente agrária. Assim, o país sustentou ao longo de décadas um desenvolvimento econômico baseado na intervenção estatal direta.

Todavia, esses projetos tiveram seu esgotamento nos anos 1980, além de receber diversas críticas dos defensores do modelo neoliberal tanto no contexto político internacional quanto nacional. Os preceitos liberais eram fortemente "protegidos" por um conjunto de leis, teorias e modelos econômicos que embasavam argumentos referentes à precariedade da ação governamental na economia e à natural melhoria do bem-estar geral através do livre fluxo de mercadorias ${ }^{3}$.

Dessa forma, o processo de descentralização administrativa do Estado, assim como a desestatização da economia com a ampla abertura aos fluxos comerciais e financeiros, se consolidaria como "verdade histórica", passando a compor o modelo de política que informaria as ações de um conjunto amplo de governos na região latino-americana.

O Brasil, ao longo da década de oitenta, com destaque especial para o período civil, vivenciou um debate teórico e político vigoroso sobre os rumos a serem traçados pela equipe econômica. A controvérsia se dava, em grande medida, entre grupos políticos dentro do PMDB e entre empresários nacionais que se contrapunham em relação à adoção do receituário liberal como solução aos problemas de desaquecimento econômico com aceleração inflacionária.

Até o final do governo José Sarney (1985-1989), esse embate permaneceu sem um grupo vitorioso claro, mas, certamente, a corrente do pensamento desenvolvimentista acabou por perder muito espaço após a saída de Dilson Funaro do Ministério da Fazenda em abril de $1987 .{ }^{4}$

Foi apenas na década de noventa que o Brasil iniciou verdadeiramente a sua entrada ao rol de países que adotaram esse conjunto sistemático e ordenado de reformas liberais, com resposta ao crescimento e desenvolvimento econômico. Entretanto, o resultado desse processo, que foi amplamente debatido neste trabalho, acabou por levar a região, e mais especificamente o Brasil, a mais uma década de estagnação social e econômica. 


\section{Modernização Perversa: as reformas liberais no Estado brasileiro}

A década de noventa no Brasil foi marcada por significativas transformações políticas e econômicas além da definitiva sedimen@ tação da democracia, principalmente após a constituição de 1988, que reverberariam de forma profunda nas relações sociais do país. $O$ país também viveria sua definitiva ruptura com o modelo desenvolvimentista, como foi citado anteriormente, adotado ao longo de décadas e que entrara em embate com percepções opostas, nesse momento predominantes nas relações políticas e econômicas.

Os primeiros anos da década de noventa foram de grandes rupturas na política internacional e de acirramento de processos transformativos na economia mundial, impactando sobremaneira as relações internacionais, as estratégias de ação internacional e a dinâmica política dos países. Simultaneamente, o Brasil passava por transformações políticas domésticas também altamente significativas, além de traçar, implementar e consolidar uma nova matriz.

A partir da entrada de Fernando Collor de Mello à Presidência da República (1990-1992), efetuou-se uma ruptura com os preceitos desenvolvimentistas, em atuação desde a década de trinta. Sua ascensão marca, de fato, o início de um conjunto de alterações nas visões e ações brasileiras, passando a viver um período de rápida abertura comercial e de liberalização financeira ${ }^{5}$. A aproximação com as grandes potências, em especial os Estados Unidos, e abertura econômica eram, na visão do governo, uma estratégia fundamental na inserção benéfica do Brasil no contexto internacional. Isso, baseado numa configuração de poder global e nos avanços da globalização, o qual os EUA se apresentavam, com o fim da Guerra Fria, como superpotência única.

Em seu governo, teve início - ao que se denomina na literatura sobre reforma do Estado - as reformas de primeira geração. Essas abrangiam, fundamentalmente: a) busca pela estabilidade de preços, através da adoção de planos econômicos para controle inflacionário, majoritariamente de caráter ortodoxo-recessivo; b) abertura incondicional ao exterior, no que se refere à liberalização comercial e fim do controle dos fluxos de capitais; c) desestatização da economia, com 
a venda das empresas estatais, e; d) criação de agências reguladoras, colocando o Estado numa nova posição estratégica na economia, executando a função de regulação de determinados setores.

Assim, o Brasil experimentou, principalmente, dois processos drásticos de ruptura econômica: abertura comercial e desestatização ${ }^{6}$. Em março de 1990, o Presidente Fernando Collor de Mello enviou ao Congresso Nacional a Medida Provisória de número 115, que veio a se tornar a Lei 8.031 por decreto presidencial, em 12 de abril do mesmo ano. Nesse momento, era instituído o Programa Nacional de Desestatizações (PND), tornando-se o principal instrumento para o processo de privatizações no Brasil.

O PND teve como principais objetivos o reordenamento da posição estratégica do Estado brasileiro na economia, implicando num processo gradual de retirada do Estado das atividades econômicas, especialmente no que se refere à posição de produtor de bens de consumo e de produção ${ }^{7}$. O plano tinha em seu preâmbulo, a noção da necessidade de se dissociar a política e a economia, com o objetivo de impulsionar uma modernização da economia brasileira. O intuito era influenciar e incentivar os investimentos produtivos privados.

Nesse sentido, o PND trouxe em seu escopo o objetivo de: através da vendas das empresas estatais brasileiras reduzir a dívida pública do país com a captação de recursos advindos da iniciativa privada nacional e internacional; modernizar o parque industrial brasileiro, ligeiramente estagnado com a diminuição acentuada do ritmo de crescimento da economia após a crise da dívida externa; e facilitar a retomada dos investimentos no país.

Ao longo do curto governo de Fernando Collor foram vendidas 18 empresas, com destaque para os setores de Siderurgia ${ }^{8}$, Petroquímica e Fertilizantes. Entretanto, nessa primeira fase das privatizações no país, ficaram fora do processo de alienação os monopólios de telecomunicações e do petróleo, respectivamente Telebrás e Petrobrás, além do Banco do Brasil S.A. ${ }^{9}$. Nesse período as vendas acabaram por arrecadar média de US\$ 4 bilhões.

Formalmente, o PND procurou adequar o processo de privatizações à situação macroeconômica vivenciada àquele momento, através da permissão para que os investidores se utilizassem de títulos de dívida pública para comprar ações das empresas brasileiras. 
Ao mesmo tempo em que essa prática respondia à necessidade de controlar a inflação galopante e os aumentos da dívida pública, ela minimizou os efeitos reprodutivos em termos de crescimento e poupança das vendas das empresas brasileiras (GIAMBIAGI; PINHEIRO, 1999, p. 23-24).

Simultaneamente ao processo de desestatização, o governo Collor iniciou uma abertura incondicional do mercado brasileiro às importações. Essas duas iniciativas se fundamentavam nas mesmas premissas de corte liberal, que acentuavam a eficiência do mercado sobre a desestabilização crônica produzida pela intervenção estatal; competitividade positiva à economia brasileira, resultante de uma alocação perfeita de recursos; incentivos aos investimentos tecnocientíficos, fruto da maior concorrência.

Consequentemente a essas variantes, as reformas produziriam maior bem-estar - medido em termos de consumo - à população e à livre concorrência. A exposição da economia brasileira ao mercado internacional traria ganhos de eficiência técnica e tecnológica, pressionando as empresas nacionais a renovarem seus processos produtivos em busca de novos "nichos" de mercado, estimulando-as à pesquisa e desenvolvimento (P\&D) - argumentavam os seus críticos ${ }^{10}$.

A saída de Collor da Presidência gerou, inicialmente, sérias dúvidas sobre os rumos políticos do Brasil, inclusive, por causa da baixa popularidade de seu vice, Itamar Franco, que assumira o poder no país após o impeachment. Logo após a entrada de Itamar, deu-se início a revisão de diversas privatizações impostas pelo PND, uma das principais políticas econômicas de seu antecessor. Tinha como objetivo procurar falhas ou desvios nos processos de vendas das estatais. Todavia, após três meses de interrupção no processo de desestatização, o programa foi reiniciado.

Apesar de o ex-presidente Itamar Franco proclamar em seus discursos a defesa da soberania nacional, além de ter estagnado por três meses as privatizações, seu governo manteve a programação do PND. O montante da arrecadação proporcionada foi de US \$ 4,5 bilhões. Seu governo nada mais fez que prosseguir o que já havia sido posto na Lei 8031/90, alienando entre 1993 e 1994 um total de 15 empresas estatais. 
Entretanto, o governo de Itamar Franco conseguiu manter a estabilidade política e iniciou o processo definitivo de estabilização e controle inflacionário do país, o Plano Real. Esse, ainda em finais de 1993, com a adoção de uma política de ajuste fiscal preparatória, foi plenamente estabelecido com a conversão da URV em Real no governo Fernando Henrique Cardoso (FHC). O Plano Real permitiu a FHC - que foi Ministro da Fazenda do governo de Itamar - uma vitória relativamente fácil nas eleições de 1994, contra o seu rival de esquerda, Luiz Inácio Lula da Silva.

A equipe econômica durante o governo Fernando Henrique Cardoso (1995-2002) tratou de intensificar o processo de privatizações iniciado nos anos Collor, tornando-o o principal instrumento de desestatização e reforma do Estado. Através da Lei n ${ }^{\circ}$ 9491, sancionada em 09 de setembro de 1997, revogou a Lei n 8031/90, que criou o Programa Nacional de Desestatização, dando novas e maiores providências ao programa.

A nova legislação introduziu no Plano, como órgão superior de decisões, o Conselho Nacional de Desestatização (CND), diretamente subordinado ao Presidente da República. O conselho especialmente criado para essa incumbência teria como objetivo fundamental a recomendação, para aprovação do Presidente da República, da inclusão ou exclusão de empresas, serviços públicos e inclusive instituições financeiras do programa de desestatização.

No processo de reformas implementado no Programa Nacional de Desestatizações, foram adicionadas, além dos setores já privilegiados na primeira fase de vendas, empresas relacionadas aos serviços públicos fundamentais, assim como uma política de fim de monopólios estatais. Entre as quais: telecomunicações - Telebrás, através de uma emenda constitucional de 1995 - e da Petrobras, através da Lei ${ }^{\circ}$ 9478/97, com a abertura das atividades de exploração da indústria petrolífera em território nacional (BRASIL. Lei $\mathrm{n}^{\circ}$ 9478, de 06 de agosto de 1997).

Soma-se a esses, a implementação da Lei no 9790/99 que promulgava formas de atuação entre o Estado e as Organizações da Sociedade Civil de Interesse Público (OSCIP). Essa lei visava esclarecer e providenciar a delegação de obrigações do Estado para 
as Organizações Sociais, que devem ser constituídas como pessoas jurídicas de direito privado e sem fins lucrativos.

Nesse sentido, o Estado promovia o receituário de descentralização, baseado na "boa governança" exigida pelas organizações internacionais como Banco Mundial (BM) e o Fundo Monetário Internacional (FMI), assim como pelos países desenvolvidos - mais especificamente Europa ocidental e EUA ${ }^{11}$. Essa reforma centravase na concepção dos mecanismos de "saída" e "voz" - exit and voice -, ao qual promoveria maior participação da sociedade civil, maior responsabilização política (accountability) e promover maiores informações aos cidadãos (OLOWU; WUNSCH, 2004, p. 70)

A lei 9790/99 dispôs as finalidades de atuação das OSCIP, através da apresentação de projetos, em áreas como:

i) promoção da assistência social; ii) promoção da cultura, defesa e conservação do patrimônio histórico e artístico; iii) promoção gratuita da educação; iv) promoção gratuita da saúde; v) promoção da segurança alimentar e nutricional; vi) defesa, preservação e conservação do meio ambiente e promoção do desenvolvimento sustentável; vii) promoção do voluntariado; viii) promoção do desenvolvimento econômico e social e combate à pobreza; ix) experimentação, não lucrativa, de novos modelos sócio-produtivos e de sistemas alternativos de produção, comércio, emprego e crédito; x) promoção de direitos estabelecidos, construção de novos direitos e assessoria jurídica gratuita de interesse suplementar; xi) promoção da ética, da paz, da cidadania, dos direitos humanos, da democracia e de outros valores universais; xii) estudos e pesquisas, desenvolvimento de tecnologias alternativas, produção e divulgação de informações e conhecimentos técnicos e científicos que digam respeito às atividades mencionadas neste artigo (BRASIL. Lei ${ }^{\circ}$ 9790, de 23 de março de 1999).

Estes programas de reforma estatal visavam, à época, serem essenciais à necessidade de aumentar a eficiência político-administrativa e econômica nacional, além de financiar o déficit fiscal, 
reduzindo a necessidade de contrair empréstimos. Seu processo foi acelerado e potencializado pelas diversas crises econômicas internacionais - crise mexicana, crise russa e crise asiática - que nas palavras de Giambiagi e Pinheiro (2000, p. 33), “[...] a privatização poderia dar ao Brasil uma vantagem sobre outros países que haviam sido ou poderiam ser vítimas de ataques especulativos".

O desmonte do Estado brasileiro se deu através de um conjunto de ações organizadas e empreendidas pelo governo. Tanto a passividade nas negociações comerciais, nas relações com os Estados Unidos, além da adequação sem qualquer contestação às regras internacionais, está diretamente relacionada ao modelo econômico e às preferências políticas emanadas do Executivo Federal. De acordo com Giambiagi e Pinheiro a "[...] privatização cumpriu seu papel de 'sinal de compromisso' com os fundamentos, como fizera na década de 90” (GIAMBIAGI; PINHEIRO, 2000, p. 34).

Num de seus artigos, Luiz Felipe Lampréia - Ministro de Estado das Relações Exteriores do Brasil, de 1995 a 2000 -, sustentava bem a visão de mundo sobre a necessidade de adequação do país a ordem global prevalecente. Baseava-se na perspectiva de que a "[...] vitória da ideia da livre iniciativa, imperatividade da disciplina fiscal e monetária, liberalização do comércio de mercadorias, serviços e dos fluxos financeiros, além de avanços fundamentais como a União Econômica e Monetária na Europa [...]", delineavam as ações no mundo globalizado (LAMPREIA, 1998, p. 5).

Dessa forma, ao final de doze anos - entre os governos Collor de Mello e FHC -, as privatizações tanto estaduais quanto federais chegaram a uma arrecadação histórica de US\$ 93,424 bilhões. O Gráfico 1 demonstra de forma ampla os valores arrecadados em toda a década de 1990, enquanto na Tabela 1 podemos ainda observar com mais detalhes algumas características do processo de privatização e seus resultados. 
Gráfico 1 - Brasil: arrecadação das privatizações 1990/2002.

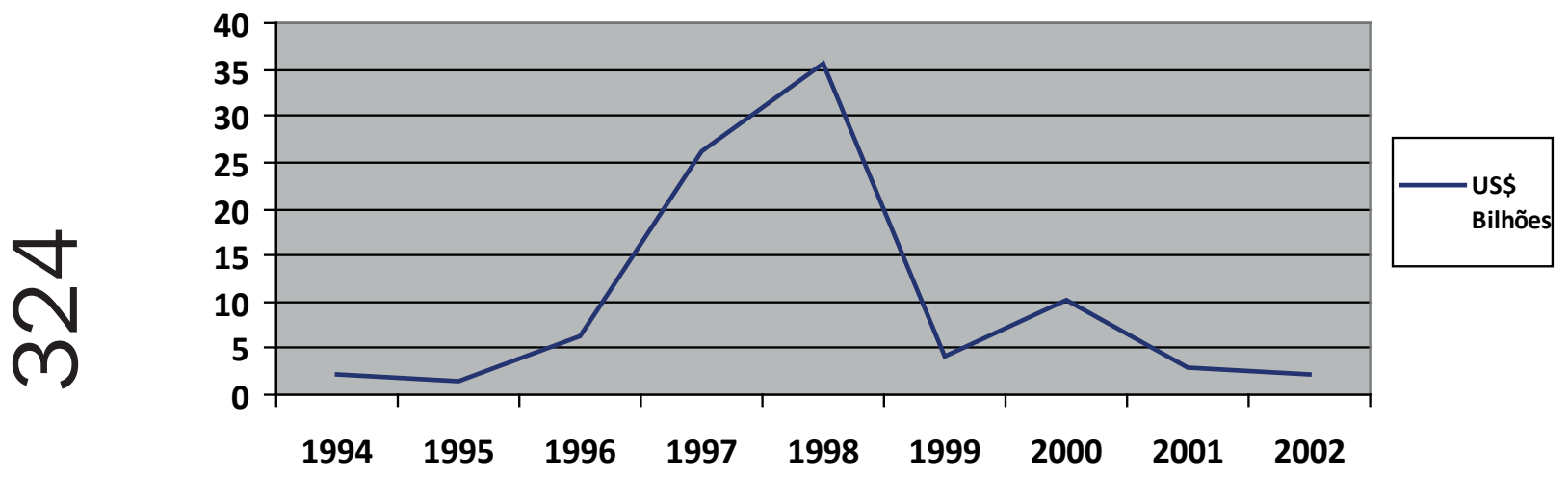

Fonte: BNDES.

Tabela 1 - Brasil: Setores e empresas privatizadas

\begin{tabular}{|c|c|c|c|c|}
\hline Período & Governo & $\begin{array}{c}\text { Principais } \\
\text { Setores }\end{array}$ & \begin{tabular}{|c|}
$\mathrm{N}^{\mathbf{2}}$ \\
Empresas
\end{tabular} & $\begin{array}{c}\text { Valor } \\
\text { (US\$ Bilhões) }\end{array}$ \\
\hline $\begin{array}{l}1990- \\
1992\end{array}$ & $\begin{array}{l}\text { Collor } \\
\text { de Mello }\end{array}$ & $\begin{array}{l}\text { Siderúrgico, } \\
\text { Fertilizantes, } \\
\text { Petroquímica }\end{array}$ & 18 & 4,0 \\
\hline $\begin{array}{l}1993- \\
1994\end{array}$ & $\begin{array}{l}\text { Itamar } \\
\text { Franco }\end{array}$ & $\begin{array}{l}\text { Siderúrgico, } \\
\text { Fertilizantes, } \\
\text { Petroquímica }\end{array}$ & 15 & 4,5 \\
\hline $\begin{array}{l}1995- \\
1996\end{array}$ & $\begin{array}{c}\text { Fernando } \\
\text { Henrique } \\
\text { Cardoso }\end{array}$ & $\begin{array}{l}\text { Químico, } \\
\text { Elétrico, } \\
\text { Ferroviário, } \\
\text { Serviços. }\end{array}$ & 19 & 5,1 \\
\hline $\begin{array}{l}1997- \\
2002\end{array}$ & $\begin{array}{c}\text { Fernando } \\
\text { Henrique } \\
\text { Cardoso }\end{array}$ & $\begin{array}{c}\text { Elétrico, } \\
\text { Ferroviário, } \\
\text { Rodoviário, } \\
\text { Mineração, } \\
\text { Financeiro, } \\
\text { Telecomuni- } \\
\text { cações, } \\
\text { Portuário. }\end{array}$ & 16 & $\begin{array}{c}81,4^{*} \\
\left({ }^{*} \text { Federais }\right. \\
\text { e Estaduais) }\end{array}$ \\
\hline
\end{tabular}

Fonte: BNDES. 
Pode ser percebido, através do Gráfico 1 e da Tabela 1, o aumento expressivo no montante arrecadado pelas privatizações a partir de 1997. Isso se deu pelas reformas nas leis de desestatização e do petróleo, cuja venda da empresa Telebrás rendeu, sozinha, mais de US $\$ 20$ bilhões aos cofres públicos do país. Com a abertura e a maior facilidade de alienação das estatais, o PND resultou em grandes operações ao longo do governo Cardoso, responsável pela arrecadação de US\$ 86,5 bilhões ao Estado.

\section{A cooptação do BNDES na lógica liberal de desenvolvimento}

A criação do Banco Nacional do Desenvolvimento Econômico e Social (BNDES) é ocorreu em 1952, tendo como principais bases de atuação o forte vínculo com as diretrizes governamentais. Entre os anos 1950 e 1970, o BNDES teve grande atuação no modelo desenvolvimentista implementado no país, constituído como um dos principais instrumentos de fomento às metas traçadas pelo Estado.

Em meados da década de 1980, o BNDES enfrentou problemas de "identidade" associada à crise do modelo desenvolvimentista - trabalhadas anteriormente nesse artigo - nos países do "Terceiro Mundo". Por outro lado, o discurso liberalizante e privatizante da Escola Liberal ganhou força - principalmente à época de Ronald Reagan e Margaret Tatcher -, ao qual foi conquistando, progressivamente, espaço dentro da tecnocracia estatal.

O BNDES passou por profundas mudanças nos anos 1990, associadas à emergência de uma nova estratégia de inserção internacional e de desenvolvimento. A reforma teve início com a reformulação da atuação do banco, tornando-se gestora direta do Plano Nacional de Desenvolvimento. Entretanto, só em meados de 1994, a atuação do banco tornou-se plenamente articulada às concepções do modelo do liberalismo econômico, assim como com suas especificidades domésticas.

Esse interregno se deu no governo Collor de Mello, em vista dos problemas enfrentados, pelo então ex-presidente, nas próprias reformas estruturais. Devido a diversos fatores políticos - como a falta de ampla base de apoio no Congresso Nacional, diversos casos 
de corrupção envolvendo seu governo e, posteriormente, processo de impeachment que acabou em sua renúncia - e econômicos - alta inflação, baixo crescimento econômico e dificuldades na estabilização de preços.

Com o aprofundamento das reformas liberais pós-1994, o BNDES além de gestor do PND tornou-se também instituição de financiamento aos programas de privatização nas esferas federal, estadual e municipal. Soma-se a isso, o papel ativo desempenhado na consolidação e reestruturação da economia brasileira, à época analisada. $\mathrm{O}$ banco passava a financiar diversos setores econômicos desestatizados, a apoiar a reestruturação industrial e a atuar como agência de financiamento às exportações brasileiras (PRATES, CINTRA e FREITAS, 2000, p. 90).

A partir de 1995, o BNDES passou a conceder também financiamento às empresas multinacionais, dada a Emenda Constitucional n. 6, que revogou o Art. 171 da Constituição Federal de 1988, ao qual havia uma distinção não isonômica entre as "empresas brasileiras de capital nacional" e as que não eram assim classificáveis. O Art. 171 da Constituição tinha como principais propósitos:

i) conceder proteção e benefícios especiais temporários para desenvolver atividades consideradas estratégicas para a defesa nacional ou imprescindíveis ao desenvolvimento do País; ii) estabelecer, sempre que considerar um setor imprescindível ao desenvolvimento tecnológico nacional [...]. Na aquisição de bens e serviços, o Poder Público dará tratamento preferencial, nos termos da lei, à empresa brasileira de capital nacional (BRASIL, Art. 171 da Constituição Federal, 1988).

A Emenda $n^{\circ} 06$ acabou por eliminar a distinção entre empresa de capital nacional e estrangeiro e igualou as condições de acesso ao crédito advindos das agências oficiais de fomento - entre elas o BNDES - e de incentivos e subsídios governamentais. No período analisado, um dos setores que mais obtiveram recursos do Banco foi o automobilístico, dominado por montadoras multinacionais, concedendo, igualmente, empréstimos às empresas multinacionais que participaram dos processos de concessão de serviços públicos 
nas áreas de transporte, energia e telecomunicações (PRATES, CINTRA e FREITAS, 2000, p. 90).

Em meados de 1997, o BNDES, por determinação do Conselho Nacional de Desestatização (CND), definido na Lei 9491/97 e, em caso de solicitação de estados federados ou municípios, poderia supervisionar o processo de desestatização de empresas controladas por aquelas unidades federadas, detentoras de concessão, permissão ou autorização para prestação de serviços públicos. O BNDES seria, portanto, o gestor do Fundo Nacional de Desestatizações (FND). Competia ao mesmo:

i) fornecer apoio administrativo e operacional, necessário ao funcionamento do Conselho Nacional de Desestatização, aí se incluindo os serviços de secretaria; ii) divulgar os processos de desestatização, bem como prestar todas as informações que vierem a ser solicitadas pelos poderes competentes; iii) constituir grupos de trabalho, integrados por funcionários do BNDES e suas subsidiárias e por servidores da Administração direta ou indireta requisitados [...] para o fim de prover apoio técnico à implementação das desestatizações; iv) promover a contratação de consultoria, auditoria e outros serviços especializados necessários à execução das desestatizações; [...] v) preparar a documentação dos processos de desestatização, para apreciação do Tribunal de Contas da União; e, vi) submeter ao Presidente do Conselho outras matérias de interesse do Programa Nacional de Desestatização (BRASIL, Lei 9491 de 09 de setembro de 1997).

Ao longo dos processos de reformas estatais da década de 1990 no Brasil, foram modificadas as diretrizes de atuação das empresas estatais, tendo um impacto mais direto nos pressupostos do BNDES. Passava de um banco de fomento ao desenvolvimento econômico de empresas de capital nacional, para uma instituição de apoio aos processos de alienação estatal e fundo gestor da arrecadação das mesmas.

Só ao final do governo Cardoso o BNDES buscou retomar mesmo que de uma forma incipiente - uma visão de financiamento e empréstimos às empresas nacionais. Em 2002, foi aberta uma linha 
de empréstimos com o objetivo de orientar, estimular e fortalecer a inserção do Brasil no mercado internacional, percebendo que o maior problema e restrição ao crescimento econômico é resultado da vulnerabilidade externa - tendo em vista o próprio processo eleitoral de 2002.

Criou-se um "Grupo de Trabalho" para examinar o tema de investimento direto no exterior e as possibilidades de integrações produtivas no hemisfério sul - principalmente voltadas à América Latina e ao continente africano. Para tanto, houve um envolvimento de outras instâncias federais, como o Ministério das Relações Exteriores (MRE) e o Ministério do Desenvolvimento, Indústria e Comércio Exterior (MDIC).

\section{Novas visões estratégicas: mudança política e econômica no século XXI}

Com a vitória de Luiz Inácio Lula da Silva, em fins de 2002, teve início uma nova forma de inserção e autonomia no contexto global. Neste sentido, foram adotadas medidas visando findar o processo de privatizações ocorridas no país e formular novos meios de atuação do Estado no desenvolvimento do país. Para isto, contou com a criação, em 2004, da Política Industrial, Tecnológica e de Comércio Exterior ${ }^{12}$; incentivos ao processo de exportação de produtos nacionais; formatação do Programa de Aceleração do Crescimento (PAC); criação dos programas de distribuição de renda, como o Bolsa Família; fortalecimento de empresas estatais; e, reformulação da atuação e dos investimentos dos bancos públicos federais.

Esses mecanismos de aporte estatal tiveram resultados visíveis na taxa de crescimento econômico e na diminuição da pobreza, levando, consequentemente, a um maior consumo de produtos duráveis e semi-duráveis ${ }^{13}$. Essa política visou o fortalecimento do mercado doméstico brasileiro, diminuindo a dependência e a intensidade das crises sistêmicas do modo de produção capitalista que nos atingiam.

A política de desenvolvimento econômico passou a estabelecer macrometas na perspectiva de auferir os resultados propostos em seu escopo. Para isso, previa o aumento da formação bruta de capital fixo, aumento dos investimentos em pesquisa e desenvolvimento (P\&D), - tanto públicos quanto privados - e a ampliação das micro 
e pequena empresas nas exportações brasileiras. Somou-se a isto, o incentivo ao processo de industrialização com vistas a fortalecer as indústrias nacionais e dar novos seguimentos em matéria de inovações tecnológicas para a competição no mercado internacional. ${ }^{14}$

Além destes mecanismos governamentais, houve um maior aporte aos bancos federais, com a finalidade de aumentar a oferta de créditos no mercado doméstico e alavancar a construção civil. Tem-se como exemplo o ocorrido com o Banco Nacional de Desenvolvimento Econômico e Social (BNDES), chegando este, a ter recursos disponíveis em maior volume que o Banco Interamericano de Desenvolvimento (BID). ${ }^{15}$

Nesse intuito, o BNDES teve como característica - além deste aporte de verbas - o projeto de expansão e de internacionalização de empresas brasileiras no exterior. Entre estas medidas está o financiamento de recursos a países. Em contrapartida estes teriam como obrigação a contratação de empresas brasileiras, em detrimento da concorrência. Esse processo de expansão se encontra bem consolidado na América do Sul e em vias de crescimento acentuado no continente africano, estando bem presentes, empresas brasileiras do setor da construção civil e de commodities.

Seguindo essas indicativas, o BNDES recebeu um plano de ampliação de capital para investimento, disponibilizando até o final de 2010, um total de 210 bilhões de reais. Essa contribuição tem como intuito a necessidade de formação bruta de capital fixo e fortalecimento das empresas nacionais, além de apoiar fortemente a internacionalização de empresas brasileiras no exterior. ${ }^{16}$

Cabe observar que, até recentemente, os casos bem-sucedidos, advindos dos processos de internacionalização das empresas brasileiras, decorreram, quase exclusivamente, da iniciativa das próprias corporações, não sendo baseados numa política deliberada de apoio governamental à criação de multinacionais brasileiras - cujas concepções ao longo da década de 90 estiveram ancoradas no receituário liberal (ALEM; CAVALCANTI, 2005, p. 54).

As exportações entraram na pauta de interesse estratégico ao governo federal, sendo consideradas decisivas para a preservação do superávit na balança de pagamento. Entre as metas, estiveram: que o Brasil atingisse, até 2010, 1,25\% das exportações mundiais ${ }^{17}$; aumentasse em 10\% o número de micro e pequenas empresas 
exportadoras; e agregasse valor aos produtos exportados. ${ }^{18}$ Inseridos nessa perspectiva, estavam a ampliação e a diversificação da pauta exportadora e dos países receptores.

O Estado, assim, entraria, em contrapartida, com a isenção e desoneração de impostos para exportação, além de abrir linhas de créditos para financiamento por bancos públicos de desenvolvimento. Essas medidas podem ser observadas diretamente no quadro da balança comercial, retratado no Gráfico 2, logo abaixo, fazendo a análise de uma década - 1998 a 2008.

Gráfico 2 - Balança Comercial Brasileira (1998 - 2008)

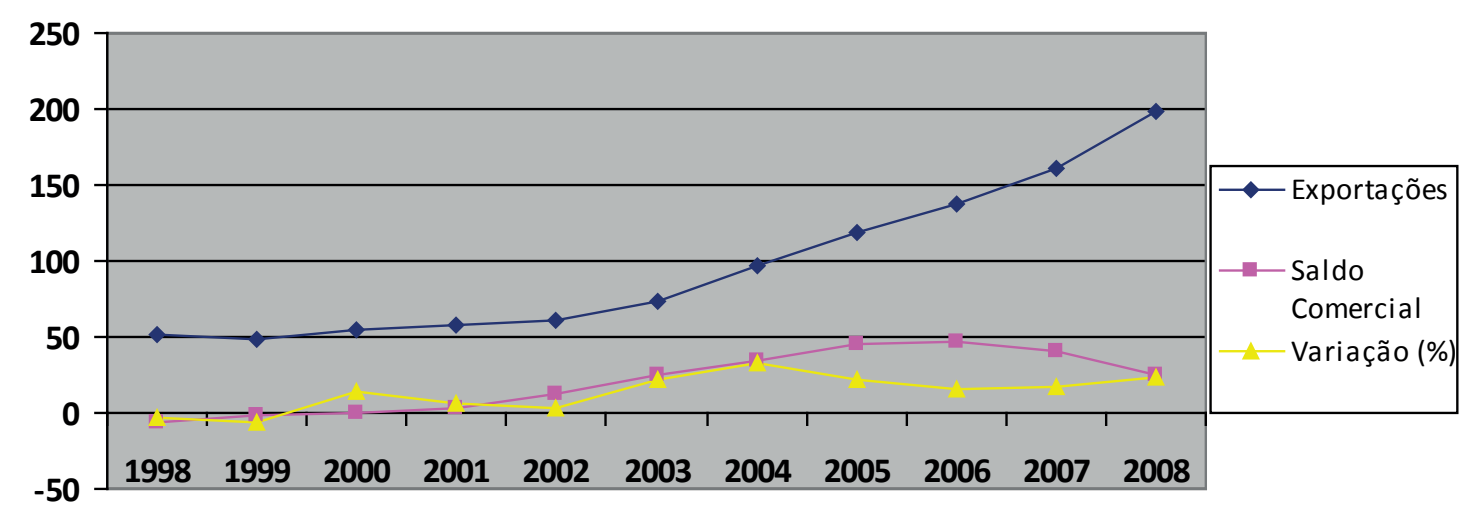

Fonte: MDIC.

Como visto na tabela acima, as macro-metas aplicadas pelo governo federal, proporcionaram uma alavancagem nas exportações e no saldo comercial brasileiro. Com relação às exportações, pode se notar que estas dobraram de 2003 a 2008, no governo atual, enquanto o saldo comercial teve uma significativa expansão, em comparação com a década passada. Entretanto, esse crescimento teve também como forte fator de alavancagem a alta das commodities no mercado internacional, contribuída pela necessidade da indústria chinesa de matérias-primas, consumindo grande parte das exportações brasileiras.

\section{Considerações Finais}

A venda das empresas brasileiras se baseava na argumentação da maior eficiência do mercado em detrimento da gestão monopolística e deficitária do Estado em setores fundamentais 
da economia. Entretanto, a arrecadação de divisas provenientes desse processo tinha o objetivo de ajudar no equacionamento das finanças públicas e incentivar a entrada de capitais, fundamental para a manutenção de um nível considerável de divisas. A abertura financeira ao capital especulativo, assim como a tentativa de angariar recursos com a disposição do patrimônio nacional e a privatização de serviços públicos era vista como necessária ao esquema de controle inflacionário, que tinha como um dos pilares fundamentais a liberalização comercial.

No entanto, a abertura comercial provocou um explosivo aumento das importações, invertendo os saldos positivos da balança comercial, que se mantiveram superavitários durante alguns anos. Como exposto no Gráfico 2 o saldo da balança comercial brasileira - exportações e importações - foi negativo entre os anos 1998 e 1999, e nulo em 2000. Só a partir de 2002, a balança comercial teve um saldo razoavelmente positivo, em vista da diminuição dos "arrochos" liberais-ortodoxos.

Assim, a queda abrupta das exportações e, por exemplo, a falência de diversas empresas pode ser explicada pelas particularidades da abertura comercial promovida no Brasil. Ao contrário de outros países que se inseriam no processo de liberalização, o Brasil diminuiu suas taxas de importação abaixo do estipulado - tanto em relação ao tempo de adequação quanto ao valor da taxa - e sem fazer os ajustes internos necessários para o choque sistêmico.

Outro fator de grande relevância na década de 1990, foi a estabilização inflacionária, que se deu com sérios custos à sociedade brasileira. A sobrevalorização da moeda nacional - o Real - frente ao dólar pressionou seguidos déficits comerciais e impactou sobremaneira alguns setores tidos, até então, como estratégicos para o desenvolvimento econômico nacional - indústrias siderúrgicas, automotivas e de alto valor agregado.

O Estado também promoveu programas de descentralização administrativa, como a delegação de responsabilidades governamentais a organizações de capital social (ONGs). Esse receituário baseou-se na concepção predominante nas relações internacionais da "boa governança", cuja ideia de "menos Estado" seria benéfica à participação popular nas decisões para o bem-estar individual e, consequentemente, para a sociedade. 
Portanto, o Brasil se abriu econômica e politicamente unilateralmente e de forma despreparada, uma vez que não buscou corrigir algumas travas internas, como tributação e alta taxa de juros, carência infraestrutural e excessiva burocracia; não dispunha de mecanismos adequados para se proteger de concorrência desleal, um mecanismo anti-dumping e de controle de preços praticados no exterior; além disso o país, historicamente, já se mostrava inepto a propiciar oportunidades de financiamentos a longo prazo para que as empresas nacionais pudessem ampliar seus investimentos e minimizar os efeitos da concorrência internacional abrupta.

Ao longo de aproximadamente doze anos (1990-2002), os governos brasileiros operaram um conjunto sistemático de políticas liberais, com destaque para, além do plano ortodoxo-recessivo de estabilização inflacionária, a abertura comercial e desestatização da economia. A adesão ao conjunto de políticas denominadas de "Consenso de Washington" colocou o Brasil, juntamente com a maioria dos "países em desenvolvimento", num caminho que levou a resultados macroeconômicos e sociais trágicos.

A alienação do patrimônio nacional para manter uma política econômica seriamente excludente, baseada na crença em soluções criadas e tabuladas em instituições internacionais, escritórios de agências de rating e experts estrangeiras para problemas genuinamente nacionais, lançou o país a vários anos de crise, estagnação e descrença. Esses resultados acabaram por sinalizar níveis paupérrimos de aprovação ao final do governo FHC, levando a processos de significativas mudanças - tanto políticas, econômicas, sociais e de atuação internacional.

\section{LIBERAL REFORMS AND DECENTRALIZATION IN BRAZIL (1990- 2002): THE PERFORMANCE OF BANCO NACIONAL DE DESEN- VOLVIMENTO ECONÔMICO E SOCIAL (BNDES)}

Abstract: Between 1990 to 2002, under the governments of Fernando Collor de Mello and Fernando Henrique Cardoso - not forgetting the interregnum Itamar Franco's governments - Brazil has deepened the process of liberal reforms. Despite adhere late the reforms, compared to other countries of South America, in that moment Brazil passed for a broad process of social, economic and administrative transformations. This restructuring was based in a new Brazil's adequacy to 


\section{Vico Dênis Sousa de Melo}

the transformations in the international relations post-Cold War. Therefore, the objective of this paper is to analyze the relation between the process of liberal reforms undertaken in Brazil - specially the trade liberalization and privatizations, beyond the decentralization's process in governmental sectors - with the strategy to be a responsible State and integrant on the new global context.

Keywords: Brazil. Liberal Reforms. Privatization. Trade Liberalization. Decentralization. BNDES.

\section{Notas}

${ }^{1}$ Uma das primeiras experiências neoliberais, aplicado em nível nacional, teve início no Chile ditatorial de Augusto Pinochet (1973-1990), com as imposições de mercado apoiados pelos Estados Unidos e os "chicago boys" - economistas formados na Universidade de Chicago alinhados à corrente neoliberal. Outras experiências viriam a ser seguidas na Argentina ditatorial (1976-1983), só como exemplo.

${ }^{2}$ Este trabalho tem o conhecimento e resguarda as peculiaridades dos processos desenvolvimentistas no Brasil entre as décadas de 1930 e 1980, em vista dos diferentes processos políticos, econômicos e históricos tanto no âmbito doméstico quanto no internacional. Dos anos trinta a início dos cinquenta, o Brasil passou por um processo de industrialização a partir das indústrias de base (siderurgia, mineração, energia etc.). Entre meados da década de 1950 a 1960, têm-se uma modernização industrial a partir dos seguimentos automotivos e da construção civil, além do momento democrático-popular no cenário doméstico. Por fim, entre 1964 a 1985, o país passou por um desenvolvimento através do endividamento externo e fundado em um regime militar autoritário e centralizador. Mesmo com essas diferenciações, ainda existem diversas peculiaridades intrínsecas nesses processos e, visando não cair em um reducionismo, faz-se relevante analisar: Furtado (1978 e 2003); Abreu (1990); Cervo (2007).

${ }^{3}$ Para uma compreensão mais adequada desse processo e das teorias que o embasava sugere-se: Moraes (2001); Cervo (2007).

${ }^{4}$ Para maiores detalhes sobre os dilemas e embates políticos nesse momento, referentes às estratégias econômicas e de política industrial, consultar: Sebastião Velasco e Cruz (1997).

${ }^{5}$ Abandonava assim, a postura combativa do Brasil nos principais fóruns multilaterais, caracterizado pela política "terceiro-mundista" implementada pelo Itamaraty, em meados de 1970 e 80.

${ }^{6}$ Vale lembrar que a estabilidade de preços foi também tentada com os Planos Collor I e Collor II. Mas, essa estabilidade só foi devidamente alcançada com o Plano Real na transição dos governos Itamar Franco e Fernando Henrique Cardoso. 


\section{Reformas Liberais e Descentralização no Brasil (1990-2002):...}

${ }^{7}$ Para uma análise mais aprofundada, ver o art. $1^{\circ}$ da lei 8.031/90. Disponível em: <http://www.planalto.gov.br/CCIVIL/Leis/L8031.htm> Acesso em: 05 out. 2011.

${ }^{8}$ A primeira empresa privatizada pelo programa foi a Usiminas, com a qual o governo arrecadou sozinho mais que todas as privatizações da década de 1980. ${ }^{9}$ Ver em: BRASIL. Lei n. 8031 de 12 de abr. de 1990

${ }^{10}$ Ver: MARKWALD, Ricardo A. O impacto da abertura comercial sobre a indústria brasileira: balanço de uma década. XII Fórum Nacional, 2001, p. 3.

${ }^{11}$ De acordo com o Banco Mundial, boa governaça é "epitomized by predictable, open and enlightened policy making; a bureaucracy imbued with a professional ethos; an executive arm of government accountable for its actions; and a strong civil society participating in public affairs; and all behaving under the rule of law. Disponível em: <http://web.worldbank.org/WBSITE/EXTERNAL/ COUNTRIES/MENAEXT/EXTMNAREGTOPGOVERNANCE/0,,conte ntMDK:20513159 pagePK:34004173 piPK:34003707 theSitePK:497024,00. html> Acesso em: 11 mar. 2012.

${ }^{12}$ Este programa foi substituído, em 2008, pela Política de Desenvolvimento Produtivo (PDP).

${ }^{13}$ Bens duráveis são os produtos figurados como eletrodomésticos, móveis e eletrônicos. O Bolsa Família é responsável pelo aumento significativo no consumo destes bens. Em pesquisas feitas pelo IBGE e pela PNAD, aponta-se taxas de crescimento do consumo popular sempre maiores que a taxa do Produto Interno Bruto Nacional (PIB): “9,25\% em 2004, 4,76\% em 2005, 6,16\% em 2006 e 9,7\% em 2007". Para observar sobre essa expansão, ver em: <http://www.mds.gov. $\mathrm{br} /$ noticias/consumo-de-bens-duraveis-aumenta-por-causa-do-bolsa-familia $>$ Acesso em: 17 mar. 2012.

${ }^{14}$ Disponível em: <http://www.desenvolvimento.gov.br/pdp/index.php/sitio > Acesso em: 17 mar. 2012.

${ }^{15}$ Em 2009, o BNDES teve o maior volume de desembolsos de sua história, com liberações de $\mathrm{R} \$ 137,3$ bilhões. O setor industrial acabou por responder pela maior parte dos desembolsos do Banco, atingindo $\mathrm{R} \$ 60,1$ bilhões. Já a infraestrutura totalizaram R \$ 46,5 bilhões. Notícia disponível em: < http:/ /www.bndes.gov.br/ SiteBNDES/bndes/bndes_pt/Institucional/Sala_de_Imprensa/Noticias/2009/ Financas/20091229_desemp_2009.html> Acesso em: 22 mar. 2012.

${ }^{16}$ De acordo com o próprio BNDES, este desembolsou um volume recorde de $\mathrm{R} \$ 137,3$ bilhões. O crescimento foi de $49 \%$ em relação aos desembolsos de 2008. Para ver mais sobre os dados de 2009, em relação aos anos anteriores efetuados pelo BNDES, ver: <http://www.bndes.gov.br/SiteBNDES/bndes/ bndes_pt/Institucional/Sala_de_Imprensa/Noticias/2009/Financas/20091229_ desemp_2009.html> Acesso em: 22 mar. 2012.

${ }^{17}$ Já em 2008, o Brasil atingiu 1,15\% das exportações mundiais. Apesar da crise financeira mundial em fins de 2008 e em 2009, e de o país sofrer uma queda em 


\section{Vico Dênis Sousa de Melo}

suas exportações, este atingiu $1,20 \%$ do total mundial, frente a queda dos principais exportadores globais. Dados disponíveis em: <www.mdic.gov.br.> Acesso em: 25 mar. 2012.

${ }^{18}$ Disponível em: <http://www.mdic.gov.br/> Acesso em: 25 mar. 2012.

\section{Referências}

ABREU, Marcelo de Paiva. "O Brasil na Rodada Uruguai do GATT: 19821993”. In: Fonseca Jr. \& Castro (Org.) Temas de Política Externa Brasileira II. Brasília: Fundação Alexandre de Gusmão, São Paulo: Editora Paz e Terra, 1994.

ALEM, Ana C.; CAVALCANTI, Carlos Eduardo. "O BNDES e o Apoio à Internacionalização das Empresas Brasileiras: Algumas Reflexões". Revista do BNDES. v. 12, n. 24, 2005.

ALMEIDA, André (Org.) Internacionalização de Empresas Brasileiras: Perspectivas e Riscos. Rio de Janeiro: Elsevier, 2007

AMBROZIO, Antonio Marcos. Entendendo o investimento brasileiro direto no exterior. Visão do Desenvolvimento: BNDES. n. 52. 2008

BATISTA JR, Paulo N. "O Plano Real a Luz das Experiências Argentina e Mexicana”. Estudos Avançados, v. 10, n. 28, p. 129-197, 1996.

BOSCHI, Renato R. DINIZ, Eli. Interesses e Mercado: Dilemas do Desenvolvimento no Brasil. Belo Horizonte: Editora UFMG/IUPERJ, 2006.

BRASIL. Constituição Federal de 1988. . Lei $n^{\circ}$. 8031, de 12 de abril de 1990. . Lei n . 9472, de 16 de Julho de 1997. . Lei n 9478, de 06 de agosto de 1997. . Lei nº. 9491, de 09 de setembro de 1997. . Lei n ${ }^{\circ}$ 9790, de 23 de março de 1999.

CERVO, Amado Luiz; BUENO, Clodoaldo. História da Politica Exterior do Brasil. Brasília: Editora da UnB, 2002

. Relações Internacionais da América Latina: velhos e novos paradigmas. Brasília: IBRI, 2001.

- Relações Internacionais do Brasil: a era Cardoso. Revista Brasileira de Politica Internacional. Brasília: IBRI, ano 45, n. 1. 2002. 


\section{Reformas Liberais e Descentralização no Brasil (1990-2002):...}

CERVO, Amado Luiz. Inserção Internacional: formação dos conceitos brasileiros. São Paulo: Saraiva, 2007.

CHANG, H-á-Joon. Chutando a Escada: a estratégia do desenvolvimento econômico em perspectiva histórica. São Paulo: Editora UNESP, 2004

COUTINHO, Luciano; FURTADO, João; AMADEU, Edward. "Política Industrial". Desenvolvimento em Debate. 2002. Disponível em: <http://www.bndes.gov.br/ SiteBNDES/export/sites/default/bndes_pt/Galerias/Arquivos/conhecimento/ livro_debate/2-PolitIndustrial.pdf> Acesso em: 23 out. 2011.

. HIRATUKI, Célio. LAPLANE, Mariano. Internacionalização e Desenvolvimento da Indústria. São Paulo: Ed. UNESP, 2004.

CYSNE, Rubens "Aspectos macro e microeconômicos das reformas brasileiras". Reformas Econômicas, n. 63, 2000.

DUPAS, Gilberto, Atores e poderes na nova ordem global: assimetrias, instabilidades e imperativos de legitimação. São Paulo: Ed. UNESP, 2005.

FURTADO, Celso, Criatividade e Dependência. São Paulo: Paz e Terra, 1978.

. Raízes do Subdesenvolvimento. São Paulo: Civilização Brasileira, 2003.

GIAMBIAGI, Fabio; PINHEIRO, Armando Castelar, “Os antecedentes macroeconômicos e a estrutura institucional da privatização no Brasil." In: FUKASAKU, Kiichiro; PINHEIRO, Armando Castelar (Org.) A Privatização no Brasil: O Caso dos Serviços de Utilidade Pública. BNDES, 1999.

GONÇALVES, Reinaldo. O Brasil e o comércio internacional: transformações e perspectivas. 2. ed. São Paulo: Contexto, 2003.

LAMPREIA, Luiz F. "Resultados da Rodada Uruguai: uma tentativa de síntese”. Estudos Avançados. v. 9, n. 23, 1995.

- A política externa do governo FHC: continuidade e renovação. In: Revista Brasileira de Política Internacional. Brasília, v. 42, n. 2, 1998.

MACIEL, George “O Brasil e o GATT”. In: Contexto Internacional, ano 2 n. 3, 1986.

MARKWALD, Ricardo A. O impacto da abertura comercial sobre a indústria brasileira: balanço de uma década. XII Fórum Nacional. 2001.

MAKWALD, Andrés. "A política externa comercial do governo Lula: o caso do Mercosul”. In: VEIGA, Pedro da Motta. (Coord.). Comércio e Política Comercial no Brasil: desempenho, interesses e estratégias. LATN/CINDES, Ed. Singular. 2007.

MARQUES, Rosa Maria; REGO, José Márcio. (Org.) Economia Brasileira. São Paulo: Saraiva. 2006. 


\section{Vico Dênis Sousa de Melo}

MORAES, Reginaldo Carmello C. Neoliberalismo: de onde vem, para onde vai? São Paulo: Editora SENAC, 2001.

OLIVEIRA, Amâncio Jorge S. N. O papel da Coalizão Empresarial Brasileira e as negociações da ALCA. Tese de Doutorado em Ciência Políticas, Universidade de São Paulo. São Paulo, 2003.

PRATES, Daniela Magalhães; CINTRA, Marcos Antonio Macedo; FREITAS, Maria Cristina Penido de. "O papel desempenhado pelo BNDES e diferentes iniciativas de expansão do financiamento de longo prazo no Brasil dos anos 90". Economia e Sociedade, n. 15, 2000.

SENNES, Ricardo. As Mudanças da Politica Externa Brasileira nos anos 80: uma potência média recém industrializada. Porto Alegre: Editora UFRGS, 2003

SILBER, Simão Davi. "Mudanças Estruturais na Economia Brasileira (19882002): Abertura, Estabilização e Crescimento". Seminário. 2002. Disponível em: $<$ http://www.usp.br/prolam/simao.pdf> Acesso em: 15 set. 2011.

VEIGA, Pedro da Motta. Politica Comercial no Brasil: desempenho, interesses e estratégias. LATN/CINDES, Ed. Singular, 2007.

VELASCO E CRUZ, Sebastião, Estado e Economia em tempo de Crise: política industrial e transição política no Brasil nos anos 80. Rio de Janeiro: Relume-Dumará; Campinas: Editora da Unicamp, 1997.

VIGEVANI, Tullo. OLIVEIRA, Marcelo F. CINTRA, Rodrigo. "Política externa no período FHC: a busca de autonomia pela integração". Revista Tempo Social, v. 15, n. 2, p. 31-61, 2004.

Recebido em 24/04/2012

Aprovado em: 02/07/2012 